\title{
A Clinical Study of Postdated Pregnancy among Patients in Dhaka Medical College Hospital
}

\author{
Dr. Dorothy Shahnaz Mukul Fatema ${ }^{1 *}$, Dr. Abdul Khaleque ${ }^{2}$, Dr. Salma Rouf ${ }^{3}$ \\ ${ }^{1}$ Department of Gynaecology and Obstetrics, Dhaka Medical College Hospital, Bangladesh \\ ${ }^{2}$ Department of Orthopaedics, Dhaka Medical College Hospital, Bangladesh \\ ${ }^{3}$ Professor, Department of Gynaecology and Obstetrics, Dhaka Medical College Hospital, Bangladesh
}

DOI: $10.36348 /$ sijog.2020.v03i09.004

| Received: 13.08.2020 | Accepted: 21.08.2020 | Published: 12.09.2020

*Corresponding author: Dr. Dorothy Shahnaz Mukul Fatema

\section{Abstract}

Introduction: Any pregnancy that has occurred beyond the expected date of delivery (EDD) is referred to as post-dated or extended pregnancy. Objective: The main objective of this study is to assess the obstetric outcome of postdated pregnancy among patients at Dhaka Medical College Hospital. Method: This was a prospective observational type study. In this study, patients who have reached 40 weeks of gestational age were included patients who were aware of the date of the last menstrual period (LMP) along with the 1st-trimester obstetrics scan. In this study, patients who were not positive were removed from LMP. The research was carried out from January 2012 to December 2013 at Dhaka Medical College Hospital. This study was selected for 250 cases purposefully observational type study. Results: The study result indicates a fetus condition among the highest $95.5 \%$ of the 250 pregnant women were alive and $4.5 \%$ died. Male baby and female babies were $49.5 \%$ and $50.5 \%$ respectively. After delivery, $75.33 \%$ of the baby admitted to the hospital, NICU $7.23 \%$, and $17.44 \%$ did not admit to the hospital. The maximum of the management of pregnant women (87.5\%) was a failure to cause oligo, and the rest was laparoscopy. Per patient operational analysis indicates the highest (75.59\%) premature membrane rupture, $17.9 \%$ ectopic pregnancy, and $6.51 \%$ uterus rupture. Conclusion: Postdated pregnancy has a $50 \%$ recurrence risk for the next birth. The infection of the fetus in the form of fetal distress, meconium aspiration syndrome, birth trauma is at high risk of pregnancy. It also improves instrument delivery and operational delivery level.

Keywords: Obstetric outcome, pregnancy postdated, last menstrual cycle.

Copyright @ 2020: This is an open-access article distributed under the terms of the Creative Commons Attribution license which permits unrestricted use, distribution, and reproduction in any medium for non-commercial use (NonCommercial, or CC-BY-NC) provided the original author and source are credited.

\section{INTRODUCTION}

Post-dated pregnancy is the pregnancy that has reached a planned delivery date of more than 42 weeks or more than 294 days. Fernandos Arias also described extended pregnancy as those pregnancies that advance beyond the expected delivery date (EDD) [1]. Nevertheless, pregnancy prolongation complicates up to $10 \%$ of all pregnancies and raises the risk of mother and fetus [2, 3]. Prolonged pregnancy incidence is only $14 \%$ of allgestations [4]. It is also difficult to explain why some women go into premature labor, while others have been pregnant for a longer time. Some common factors of postdated pregnancy are-genetic causes, high living standards, sedentary habits, anencephaly, elderly primigravidae, elderly multigravidae, etc. Specific studies indicate that past post-term pregnancy experience has a recurrence rate of $50 \%$. Also, it increases perinatal mortality and fetal morbidity when every pregnancy goes past the EDC (Expected Date of Confinement). According to United Kingdom's national birthday trust statistics in 1958, the perinatal mortality rate rises at 42 weeks of gestation, doubles at 43 weeks, and quadruples at 44 weeks of gestation [5]. Postmaturity syndrome (Fetaldysmaturity) is associated with $5-10 \%$ of extended pregnancy. These fetuses decreased the amount of subcutaneous fat and wrinkled skin (because they missed the caseosa vernix), long hair, and longfingernails. Ideally, prolonged complications of pregnancy should be detected before childbirth, as these fetuses are delicate and are frequently acidic at birth. Both baby classes have a higher perinatal mortality rate, about $1 / 4$ of death occurs in antepartum, 1/3 of intrapartum, and about 1/5 of neonatal. 


\section{OBJECTIVE}

To determine the postdated pregnancy obstetric outcome among the patients at Dhaka Medical College Hospital.

\section{METHOD}

Study type: It was a prospective observational study.

Study place and period: This research was performed from January 2012 to December 2013 atthe Department of Obstetrics and Gynecology, Dhaka Medical College Hospital.

\section{Method}

For this study, patients who have completed 40 weeks of gestational age were included patients who were aware of the last menstrual period (LMP) date along with the 1st-trimester obstetrics scan. In this study, patients who were not positive about LMP were omitted. The research was carried out for 3 years at the Department of Obstetrics and Gynecology, Dhaka
Medical College Hospital. For this analysis, 250 cases were chosen intentionally.

Data Analysis

After collection, all data were reviewed and edited during the analysis. Using window-based computer software built with Statistical Packages for Social Sciences (SPSS23) the data were then entered into the database and statistical analysis of the results was obtained. The findings were presented in figures and tables.

\section{RESULTS}

Patient age distribution ranged from 16 to 30 years for 250 pregnant women. Maximum (66\%) patients were between 26-30 ages. And minimum (10\%) patients were between 16-20 ages. The following Table-1 showed the age distribution: Fig-1 Below is showing the pie chart of the age distribution of the patients.

Table-1: Age of pregnant women

\begin{tabular}{|l|l|l|l|l|}
\hline Age & Frequency & Percent (\%) & Valid Percent (\%) & Cumulative Percent (\%) \\
\hline 16years- 20years & 25 & 10 & 10 & 10 \\
\hline 21 years- 25years & 60 & 24.0 & 24.0 & 34 \\
\hline 26 years- 30years & 165 & 66 & 66 & 100.0 \\
\hline Total & 250 & 100.0 & 100.0 & \\
\hline
\end{tabular}

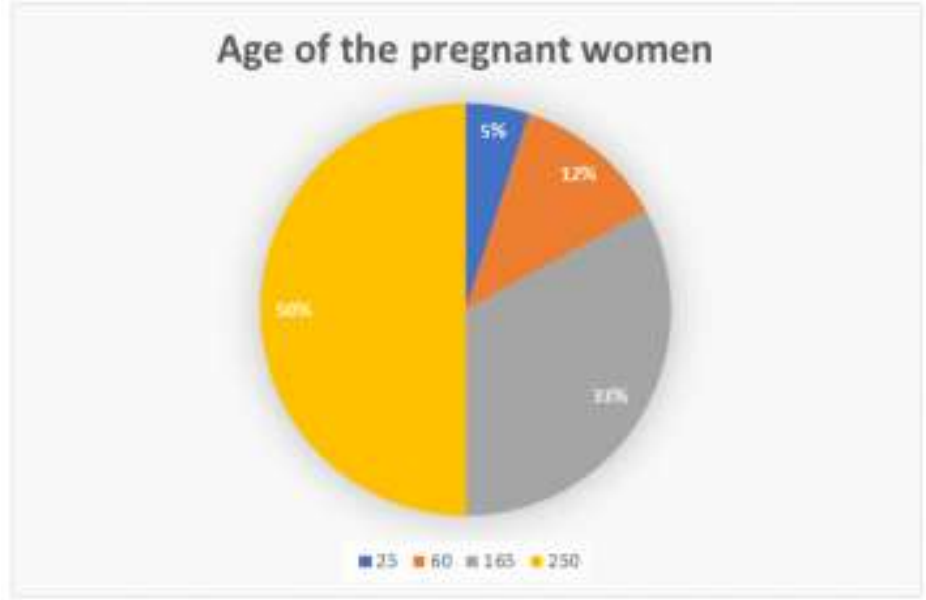

Fig-1: Age distribution

The distribution of parity among the 250 pregnant women are shown (Table-2). Here, the highest
$52.8 \%$ was Primigravida, Multigravida was $46 \%$ and the 2 nd pregnant was just $1.2 \%$. See below-

Table-2: Parity distribution of the patients

\begin{tabular}{|l|l|l|l|l|}
\hline Description & Frequency & Percent (\%) & Valid Percent (\%) & Cumulative Percent (\%) \\
\hline Primigravida & 132 & 52.8 & 52.8 & 52.8 \\
\hline 2nd pregnant & 3 & 1.2 & 1.2 & 54 \\
\hline Multigravida & 115 & 46 & 46 & 100.0 \\
\hline Total & 250 & 100.0 & 100.0 & \\
\hline
\end{tabular}


Methods of delivery among the 250pregnant women are given in Table-3. Maximum (87.2\%) patients gave birth by cesarean delivery accompanied by usual delivery of just $12.8 \%$. See below Table- 3 .

Table-3: Delivery method of the pregnancy

\begin{tabular}{|l|l|l|l|l|}
\hline Method & Frequency & Percent (\%) & Valid Percent (\%) & Cumulative Percent (\%) \\
\hline Cesarean delivery & 218 & 87.2 & 87.2 & 87.2 \\
\hline Normal delivery & 32 & 12.8 & 12.8 & 100.0 \\
\hline Total & 250 & 100.0 & 100.0 & \\
\hline
\end{tabular}

After the delivery of newborns, the male baby and female baby was $49.5 \%$ and $50.5 \%$ respectively (Figure-2).

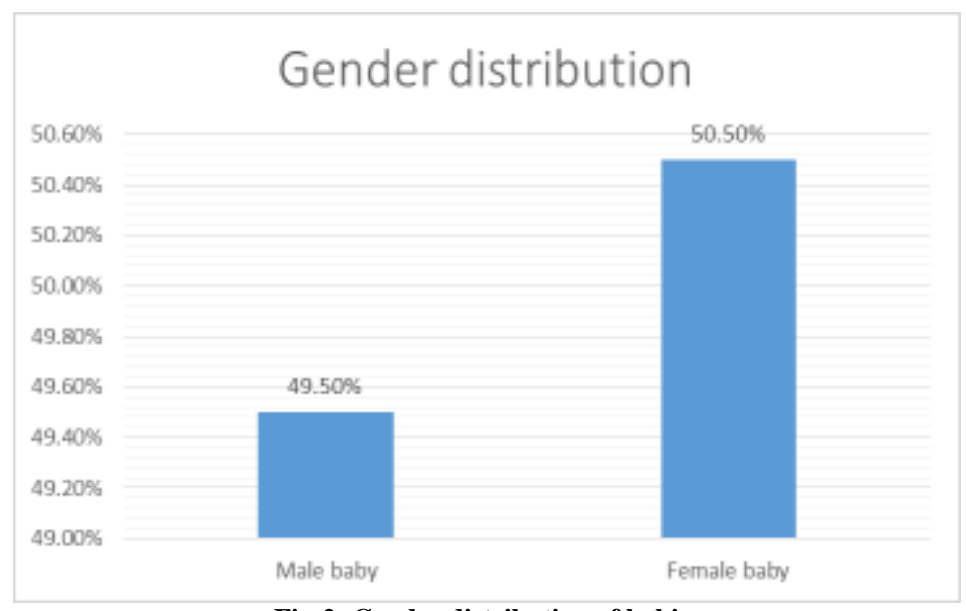

Fig-2: Gender distribution of babies

According to the condition of all the newborns, $75.33 \%$ of babies admitted to the hospital after birth, $7.23 \%$ NICU, and $17.44 \%$ of babies did not admit to the hospital (Figure-3).

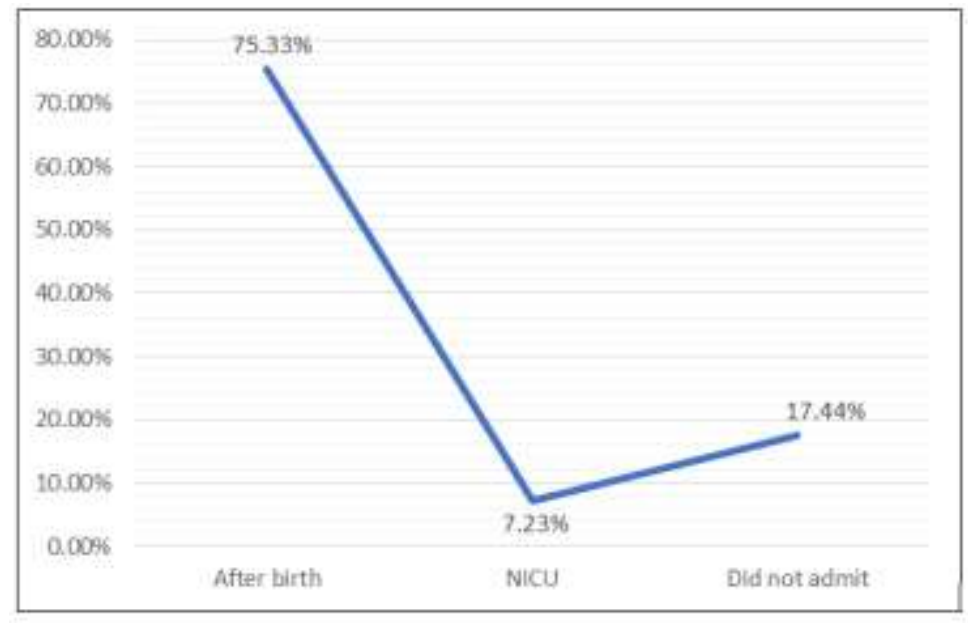

Fig-3: Hospital admission

The patient was treated accordingly based on the physical measurements collected during each visit. The study generated four types of outcomes (Table-4). 168 of 250 patients followed the spontaneous onset of labor. 19 patients also had normal physical activity until labor, which was induced by a cervix favorable to artificial membrane rupture. 21 patients showed abnormal cases, suggesting a fetal compromise constituted a definite indication of delivery, undertaken by the appropriate route within 24 hours. During their last assessment, 42 patients had a good condition but labor was induced "only for dates" despite the cervix being undesirable for artificial membrane rupture. The mean birth weight and mean gestational length have been showing in Table-4 below: 
Table-4: Management of the patients $(n=250)$

\begin{tabular}{|l|l|l|l|}
\hline Description of delivery & $\mathbf{n}$ & Mean birth weight (gm) & Mean gestational length (gm) \\
\hline Spontaneous labor & 168 & 3978 & 303 \\
\hline Induced labor/favorable cervix & 19 & 3829 & 301 \\
\hline Delivered because of fetal indications & 21 & 3621 & 299 \\
\hline Induced for dates only & 42 & 3718 & 300 \\
\hline
\end{tabular}

\section{Complications and prognosis}

Among 250 pregnant women, the highest $95.5 \%$ fetus was alive, and $4.5 \%$ were dead. Carbohydrate resistance and gestational hypertension are the primary maternal conditions that need to be removed. Ketonuria should be tested as it can alter the results of $\mathrm{w} 72 \mathrm{x}$ fetal health tests. Parity should also be taken into account, as the probability of SB in nulliparous women is increased, but not in multiparous women w47x. When fetal macrosomia is suspected, it is important to determine the maternal stature to assess the risk of traumatic delivery for both mother and newborn. Counseling can be given daily induction or expectant management after the exclusion of high-risk classes. The patient must be given details specifically detailing the costs and benefits of both management approaches. Counseling should be descriptive and notthe only guideline. Patient preference needs to be valued. The words used must be easy for patients to understand.

\section{DISCUSSION}

Postponed pregnancy is a condition with a high chance of obstetrics. Across multiple ways, perinatal mortality and morbidity became increased when pregnancy progressed beyond a period, i.e. 40 weeks. A total of 1900 patients were admitted to the antenatal and labor ward in Dhaka medical College during this study period. For the 250 pregnant women, 14 days (that is, post maturity) surpassed EDD. Some previous researches showed $3-14 \%$ and $11 \%$ incidences, respectively.

The past 40 weeks of pregnancy prolongation happen even more often than postmaturity. Beyond 4142 weeks [6-8], it was noted $10-15 \%$. The occurrence then falls within the normal limit $[9,10]$. In this study the incidence of post-dated pregnancies was more in the 26-30 year age group. Beischer et al found in his study that the majority of postdated patients belonged to the 25-30 year age group, while Bancroft et al found that the majority of patients belonged to 21-30 years [11, 12]. Reddy UM et al., found that women of advanced maternal age are at higher risk of stillbirth throughout gestation, the peak risk period is 37 to 41 weeks [13]. Form of delivery compared with pre-term pregnancy was not substantially correlated with post-dated pregnancy. Similar results were also found in a study conducted by Katz et al., who tested a non-aggressive approach to post-date pregnancy treatment involving 156 patients who had exceeded 294 days of amenorrhea with a Bishop score of 4 or less [14].

\section{CONCLUSION}

The outcomes of this prospective clinical study of a selective postdate pregnancy management strategy are very encouraging. Based on the findings we would suggest that it may no longer be reasonable to elect the routine delivery of all patients at or beyond 42 completed weeks of gestation. Postdated pregnancy has a $50 \%$ recurrence risk for the next birth. The infection of the fetus in the form of fetal distress, meconium aspiration syndrome, birth trauma is at high risk of pregnancy. One concern raised by labor induction opponents in post-term patients is that there is the potential for an increased risk of cesarean delivery with an undesirable cervix. Selective patient care appears to be the method of choice given the proven reliability of fetal assessment methods and the potential risk of nondiscriminative intervention. Future researches are encouraged to bring more benefits toall management approachesof postdated pregnancy.

\section{REFERENCES}

1. Fernando, A. (2008). Practical guide to high risk pregnancy and delivery 3 Edition; India Harcourt private limited: $255-270$.

2. Olesen, A. W., Westergaard, J. G., \& Olsen, J. (2003). Perinatal and maternal complications related to postterm delivery: a national registerbased study, 1978-1993. American journal of obstetrics and gynecology, 189(1), 222-227.

3. Norwitz, E. R., Snegovskikh, V. V., \& Caughey, A. B. (2007). Prolonged Pregnancy:: When Should We Intervene?. Clinical obstetrics and gynecology, 50(2), 547-557.

4. Ratnam, SSK Bhasker Rao, S Arulkumaran. Obstetrics and Gynaecology for PostGraduates.OrientLengmen Ltd, India, 1994; Vol 2: 90-5.

5. Goodwin, T. M., DeCherney, A., Nathan, L., \& Laufer, N. (2012). Current diagnosis and treatment obstetrics and gynecology. McGraw-Hill Medical Publishing Division., 10th ed, USA, 187-8, 283 95.

6. Rahim, A. (2000). Dissertation on Diagnosis, Management and Outcome of Prolonged Pregnancy. A Study of 50 Cases in Bangobandhu Sheikh Mujib Medical University Hospital in 2000 .

7. Matijevic, R. (1998). Outcome of Post-term Pregnancy: a Matched - Pair Case Control Study. Croat Med Journal. 39(4):430-434.

8. Arias F. Practical Guide to High Risk Pregnancy and Delivery. Mosby-year Book 2nd ed, 1993. 
9. Luckas, M., Buckett, W., \& Alfirevic, Z. (1998). Comparison of outcomes in uncomplicated term and post-term pregnancy following spontaneous labor. Journal of Perinatal Medicine-Official Journal of the WAPM, 26(6), 475-479.

10. Matijeviæ, R. (1998). Outcome of Post-Term pregnancy: Amatched-Pair case control study. Coration Medical Journal, 39(4), 55-61.

11. Beischer, N. A., Brown, J. B., Smith, M. A., Townsend, L., Beischer, N. A., Evans, J. H., \& Townsend, L. (1969). Prolonged Pregnancy. Obstetrics and Gynecology, 103, 476.
12. Bancroft- Livingston, G., \& Neill, D. W. (1957). STUDIES IN PROLONGED PREGNANCY: Part I-Cord Blood Oxygen Levels at Delivery. BJOG: An International Journal of Obstetrics \& Gynaecology, 64(4), 498-503.

13. Reddy, U. M., Ko, C. W., \& Willinger, M. (2006). Maternal age and the risk of stillbirth throughout pregnancy in the United States. American journal of obstetrics and gynecology, 195(3), 764-770.

14. Fernando, A. (2008). Practical guide to high risk pregnancy and delivery 3 Edition; India Harcourt private limited. $255-270$. 